\title{
Ability of Pit and Fissure Sealant-containing Amorphous Calcium Phosphate to inhibit Enamel Demineralization
}

\author{
${ }^{1}$ Feda I Zawaideh, ${ }^{2}$ Arwa I Owais, ${ }^{3}$ Wasan Kawaja
}

\begin{abstract}
Aim: To evaluate the effect of amorphous calcium phosphate (ACP)-containing pit and fissure sealant on inhibition of enamel demineralization in vitro.

Materials and methods: Enamel specimens $(n=75)$ were prepared using freshly extracted noncarious human third molars. Box-shaped cavities $(8 \times 2 \times 2 \mathrm{~mm})$ on the buccal or lingual surfaces were prepared and restored with resin-based sealant (Concise ${ }^{\mathrm{TM}}$ ), ACP-containing sealant (Aegis ${ }^{\circledR}$ ) or fluoride-containing sealant (Conseal- $\mathrm{F}^{\mathrm{TM}}$ ). The samples were acid challenged in a demineralizing solution of $50 \mathrm{mmol} / \mathrm{l}$ lactic acid at $\mathrm{pH} 5.0$ for 4 days. The change in enamel microhardness $(\triangle \mathrm{S} \mu \mathrm{H})$ was calculated. Data were analyzed using one-way analysis of variance (ANOVA) and Tukey's post hoc test.
\end{abstract}

Results: The mean $\mathrm{S}_{\mu} \mathrm{H}_{0}( \pm \mathrm{SD})$ (in Vicker's unit) prior to the acid challenge was: Concise ${ }^{\mathrm{TM}}(318.83 \pm 33.86)$, Aegis $\AA$ $(331.03 \pm 21.52)$, Conseal-F TM $(310.12 \pm 34.31)$. Following the acid challenge, the values dropped in all groups and $\Delta \mathrm{S} \mu \mathrm{H}( \pm \mathrm{SD})$ values were $269.17 \pm 47.49,151.39 \pm 23.96$ and $175.79 \pm 32.39$ respectively.

Conclusion: The ACP-containing pit and fissure sealant has the potential to inhibit enamel demineralization.

Keywords: Aegis ${ }^{\circledR}$, Amorphous calcium phosphate, Demineralization, Pit and fissure sealant, Surface microhardness.

How to cite this article: Zawaideh FI, Owais Al, Kawaja W. Ability of pit and fissure sealant-containing amorphous calcium phosphate to inhibit enamel demineralization. Int J Clin Pediatr Dent 2016;9(1):10-14.

Source of support: This Study was funded by the Deanship of Research at Jordan University of Science and Technology (Grant 20120058).

\section{Conflict of interest: None}

\section{INTRODUCTION}

Amorphous calcium phosphate (ACP) is a precursor to the formation of hydroxyapatite (HAP), which is the final, stable product in the precipitation of the calcium

${ }^{1}$ Assistant Professor, ${ }^{2}$ Associate Professor, ${ }^{3}$ Postgraduate Student

${ }^{1-3}$ Department of Preventive Dentistry, Jordan University of Science and Technology, Irbid, Jordan

Corresponding Author: Feda I Zawaideh, Assistant Professor, Department of Preventive Dentistry, Jordan University of Science and Technology, Irbid-22110, Jordan, e-mail: feda. zawaideh@yahoo.com and phosphate ions from neutral or basic solutions. Amorphous calcium phosphate has shown anti-cariogenic properties with remineralization potential. ${ }^{1,2}$ Amorphous calcium phosphate-containing bioactive materials stimulate mineral growth by increasing the calcium and phosphate concentrations within the lesion, especially in acidic oral environment, to levels above those existing in ambient oral fluids, thereby shifting the thermodynamic driving forces of the solution toward the formation of apatite. Amorphous calcium phosphate is believed to maintain these supersaturation conditions over extended periods of time. ${ }^{3}$

Amorphous calcium phosphate has both preventive and restorative material properties that justify its use in dental cements, sealants, composites and orthodontic adhesives. ${ }^{1,4}$ Amorphous calcium phosphate-filled composite resins have been shown to repair $71 \%$ of the lost mineral content of decalcified teeth. ${ }^{1}$

A new pit and fissure sealant containing ACP (Aegis ${ }^{\circledR}$ pit and fissure sealant) has been marketed for use as a light-cured sealant with similar properties to previously used resins. These materials are encouraging the formation of HAP, which can be used by the tooth for remineralization. The manufacturers claim that it has the ability to release calcium and phosphate ions and remineralize tooth structure by enhancing the tooth's natural repair mechanism. Silva et al $^{2}$ have demonstrated in situ the remineralization of artificially induced caries lesions by Aegis ${ }^{\circledR}$ and Choudhary et $\mathrm{al}^{5}$ demonstrated the remineralization potential of Aegis ${ }^{\circledR}$ using scanning electron microscope (SEM). Alsaffar et $\mathrm{al}^{6}$ demonstrated that Aegis ${ }^{\circledR}$ may provide some protective effect on demineralization of adjacent enamel measuring the amount of mineral loss. However, it was not superior to fluoride-releasing sealants.

The aim of this study is to evaluate the effect of incorporating ACP into pit and fissure sealant on inhibition of enamel demineralization and compare it with fluoride-releasing sealant using enamel microhardness tester.

\section{MATERIALS AND METHODS}

Ethical approval for using extracted teeth was obtained from the Institutional Review Board of Jordan University 
of Science and Technology (JUST). Freshly extracted noncarious third molars $(n=38)$ were collected from the dental clinics at JUST and stored in $0.1 \%$ thymol, to inhibit bacterial growth and were used within 4 months of extraction.

The roots of the teeth were removed perpendicular to the long axis of the tooth with a $0.3 \mathrm{~mm}$ thick diamond blade (Struers, Copenhagen, Denmark). Sound, relatively plain buccal and lingual surfaces free of cracks, stains and hypomineralized areas were selected. In order to remove the fluoride-rich surface enamel layer and to obtain a relatively flat surface, the buccal and lingual aspects of each tooth were polished with a series of aluminum oxide soflex disks (coarse, medium, fine, and superfine grit; 3M ESPE Dental Products, St Paul, MN, USA). Box-shaped cavities, $8 \mathrm{~mm}$ long $\times 2 \mathrm{~mm}$ wide $\times 2 \mathrm{~mm}$ deep, were prepared between the middle and cervical thirds of the buccal and lingual surfaces of each tooth using a flat fissure tungsten carbide bur $1 \mathrm{~mm}$ in diameter in a high-speed handpiece with air-water coolant. The cavities were prepared and finished with a slow-speed steel flat fissure bur $0.9 \mathrm{~mm}$ in diameter to create a cavo-surface angle as close as possible to $90^{\circ}$. Each crown was then sectioned into two halves in a mesiodistal direction to produce two enamel samples (buccal and lingual) (hereafter termed specimens) and stored in distilled water.

The specimens were randomly assigned into three groups one control group and two experimental groups. In group $1(\mathrm{G} 1)(\mathrm{n}=25)$, cavities were filled with conventional resin-based sealant (control group) (Concise $^{\mathrm{TM}}$ - opaque white; 3M ESPE Co. Ltd.). In group 2. (G2) $(n=25)$, cavities were filled with sealant-containing ACP (Aegis ${ }^{\circledR}$ - opaque white; Bosworth Co. Ltd.) and, in group $3(\mathrm{G} 3)(\mathrm{n}=25)$, cavities were filled with resinbased sealant-containing fluoride (Conseal-FTM; SDI). Each sealant material was used strictly according to their manufacturers' instructions.

Two coats of acid-resistant nail varnish were applied to the tooth surface, leaving a window not less than approximately $1 \mathrm{~mm}$ wide surrounding the occlusal margin. Specimens were mounted on aluminum cylinders and surface microhardness was measured by surface microhardness tester (Matsuzawa Seiki tester) in Vickers' units by applying $25 \mathrm{gm}$ of force for 5 seconds. The hardness was measured on three different locations, with
$100 \mu \mathrm{m}$ spacing and then the average of the three readings was calculated to get the baseline surface microhardness value (baseline: $\mathrm{S \mu H}_{0}$ ).

Each specimen was then stored in individual plastic containers containing $40 \mathrm{ml}$ of acid buffer solution consisting of $50 \mathrm{mmol} / 1$ lactic acid adjusted to $\mathrm{pH}$ 5.0. The teeth were stored in the demineralizing solution for 4 days at $37^{\circ} \mathrm{C}$ without refreshing the solution. After 4 days, the teeth were removed from the solution, rinsed with distilled water and microhardness measurements were recorded in the same protocol described for the baseline measurement above (final: $\mathrm{S}_{\mathrm{H}}$ ).

\section{STATISTICAL ANALYSIS}

Descriptive statistics were prepared for surface microhardness values for each group; means were compared using Statistical Package for the Social Science (SPSS) version 19.0 for Windows (SPSS Inc., Chicago, USA). Assumptions of normality and equal variance were verified and one-way analysis of variance (ANOVA) comparison of means was performed at a significance level of 0.05 . When ANOVA revealed a difference between groups, Tukey's post hoc test was performed to compare between the changes in microhardness by acid for the three groups.

\section{RESULTS}

One specimen in group 1 failed following the acid exposure resulting in 24 specimens available in this group and 25 specimens in each of groups 2 and 3.

The mean $( \pm \mathrm{SD})$ surface microhardness $\left(\mathrm{S}_{\mu} \mathrm{H}_{0}\right)$ values of the specimens for the three different treatment groups before acid challenge are shown in Table 1. There were no statistically significant differences between the surface microhardness means of the three groups before the acid challenge ( $p=0.058)$.

Following the acid challenge, the mean surface microhardness $\left(\mathrm{S}_{\mathrm{H}} \mathrm{H}_{1}\right)$ values of the three groups dropped significantly (Table 1). Group 2 had the highest mean $\mathrm{SuH}_{1}$ of $179.63 \pm 23.36$ (Vicker's unit reaching up to triple that of group 1). Statistically significant differences existed in the mean surface microhardness between the three groups following the acid challenge $(p=0.000)$.

The mean $\mathrm{S} \mu \mathrm{H}$ difference $\left(\mathrm{S} \mathrm{H}_{0}-\mathrm{S}_{\mu} \mathrm{H}_{1}\right)$ between preand postacid challenge values was calculated (Table 2).

Table 1: Surface microhardness $(\mathrm{S} \mu \mathrm{H})$ in Vicker's unit for different fissure sealant treatments before and after the acid challenge

\begin{tabular}{|c|c|c|c|c|c|c|c|}
\hline Groups & $\begin{array}{l}\text { Means of } \mathrm{S}_{\mu} \mathrm{H}_{0} \pm \\
\text { std. deviation }\end{array}$ & $\mathrm{S} \mu \mathrm{H}_{0}$ range & $p$-value* & Groups & $\begin{array}{l}\text { Means of } \mathrm{S}_{\mu \mathrm{H}_{1} \pm} \\
\text { std. deviation }\end{array}$ & $\mathrm{S} \mu \mathrm{H}_{1}$ range & $p$-value* \\
\hline G1 $(n=24)$ & $318.83 \pm 33.86$ & $274.3-401.1$ & 0.058 & G1 $(n=24)$ & $49.66 \pm 29.86$ & $16.7-126.4$ & 0.000 \\
\hline$G 2(n=25)$ & $331.03 \pm 21.52$ & 289.2-372.6 & & $\mathrm{G} 2(\mathrm{n}=25)$ & $179.63 \pm 23.36$ & $131.5-214.1$ & \\
\hline G3 $(n=25)$ & $310.12 \pm 34.31$ & $231.7-372.2$ & & G3 $(n=25)$ & $134.52 \pm 19.1$ & $95.8-180.0$ & \\
\hline
\end{tabular}

*Significant when $p<0.05$ 
Table 2: Mean microhardness change (in Vicker's unit) by application of acid for different fissure sealant groups

\begin{tabular}{|c|c|c|c|c|c|c|c|c|c|}
\hline \multirow[b]{3}{*}{ Groups } & \multicolumn{4}{|c|}{ Mean $\mathrm{S} \mu \mathrm{H}$ difference within the groups } & \multicolumn{5}{|c|}{ Mean $\mathrm{S} \mu \mathrm{H}$ difference between the groups } \\
\hline & \multirow{2}{*}{$\begin{array}{l}\text { Mean } \mathrm{S} \mu \mathrm{H} \\
\text { difference } \pm \\
\text { std. deviation }\end{array}$} & \multirow[b]{2}{*}{ Min. } & \multirow[b]{2}{*}{ Max. } & \multirow[b]{2}{*}{$p$-value* } & \multirow[b]{2}{*}{ Groups } & \multirow{2}{*}{$\begin{array}{l}\text { Mean } S \mu H \\
\text { difference } \pm \\
\text { std. error }\end{array}$} & \multicolumn{2}{|c|}{$\begin{array}{l}95 \% \text { confidence } \\
\text { interval }\end{array}$} & \multirow[b]{2}{*}{$p$-value* } \\
\hline & & & & & & & $\begin{array}{l}\text { Lower } \\
\text { bound }\end{array}$ & $\begin{array}{l}\text { Upper } \\
\text { bound }\end{array}$ & \\
\hline G1 $(n=24)$ & $269.17 \pm 47.49$ & 168.64 & 379.33 & 0.000 & G1-G2 & $117.78 \pm 10.22$ & 97.40 & 138.16 & 0.000 \\
\hline$G 2(n=25)$ & $151.39 \pm 23.96$ & 99.36 & 201.39 & & G1-G3 & $93.50 \pm 10.22$ & 73.12 & 113.89 & 0.000 \\
\hline G3 $(n=25)$ & $175.79 \pm 32.39$ & 110.09 & 224.85 & & G2-G3 & $24.28 \pm 10.12$ & 4.10 & 44.45 & 0.019 \\
\hline
\end{tabular}

*Statistically significant if $p<0.05$

Measurements following the acid application were significantly lower for all fissure sealant groups than those prior to the acid application. The amount of difference was highest in group 1 followed by group 3 . A statistically significant difference existed between the three groups with $\mathrm{p}=0.000$.

Multiple comparisons of the mean $\mathrm{S} \mu \mathrm{H}$ difference among the three groups detected a statistically significant relationship ( $p=0.000)$ between groups 1 to 3 . There was also a significant difference between the two treatment groups 2 and $3(p=0.019)$.

\section{DISCUSSION}

\section{Effect of ACP-containing Fissure Sealant on inhibition of Demineralization}

Amorphous calcium phosphate-containing fissure sealant was shown to be effective in inhibition of enamel demineralization. This is in agreement with the previous in vitro and in situ studies. ${ }^{2,5,6}$ Silva et $\mathrm{al}^{2}$ demonstrated in situ that sealants containing ACP and/or fluoride presented a higher remineralizing capacity than that of the control group, but the sealants containing ACP provided either more efficient or similar remineralization, than the other sealants containing fluoride. They were able to promote remineralization of artificially induced carious lesions on the smooth enamel surfaces. ${ }^{2}$

A recent in vitro study was conducted by Choudhary et $\mathrm{al}^{5}$ to evaluate the remineralization potential of ACP and fluoride-containing pit and fissure sealants using SEM. After $\mathrm{pH}$ cycling, qualitative changes at the tooth surface and sealant interface were examined. The presence of white zone at the interface was considered positive for remineralization. Both ACP-containing and fluoride-containing groups showed white zone at the tooth surface-sealant interface. However, the white zone in the ACP group had irregular, granular or globular zone evident in few areas, while granular or globular zones were not evident in the fluoride-releasing group. They concluded that both ACP- and fluoride-containing sealants had the potential for remineralization. The release of ACP molecules in the ACP group and formation of fluorapatite in the fluoride group were responsible for the remineralization. ${ }^{5}$

\section{Effect of Fluoride-releasing Fissure Sealant on inhibition of Demineralization}

The effectiveness of fluoride released from various dental materials in caries prevention by promoting remineralization and inhibiting demineralization of enamel has been widely demonstrated. ${ }^{7,8}$

However, clinical studies exhibited conflicting data as to whether or not these fluoride-containing materials significantly prevent or inhibit secondary caries and affect the growth of cariogenic bacteria compared with nonfluoridated materials. ${ }^{9}$ A study conducted by Vatanatham et $\mathrm{al}^{9}$ showed that the mineral loss of incipient enamel carious lesions sealed with fluoride-containing sealants was not significantly different from those of nonfluoridecontaining sealants. Short- and long-term fluoride releases from restoratives are related to their matrices, setting mechanisms and fluoride content and depend on several environmental conditions. ${ }^{9}$

In our study, Conseal-FTM provided increased demineralization inhibition compared to conventional sealant containing no fluoride. This is in accordance with many in vitro studies. ${ }^{6,10}$

Garçía-Godoy et $\mathrm{al}^{11}$ conducted a study to compare the amounts and patterns of fluoride release from five different fluoride-containing pit and fissure sealants. They found that all fluoride-containing sealants released fluoride in the same pattern throughout the test period of 30 days; i.e., the greatest amount of fluoride was released in the first 24 hours after mixing, fell sharply on the second day and decreased slowly in the final days. ${ }^{11}$

Fluoride released from glass ionomer cement (GIC)based dental materials was significantly more than fluoride released from resin-based materials containing fluoride. ${ }^{12}$ Studies on fluoride release from pit and fissure sealants demonstrated the same findings. Salar et $\mathrm{al}^{10}$ found that incorporation of fluoride into sealants provided increased demineralization inhibition compared with a conventional 
sealant containing no fluoride, but less than that shown by a glass ionomer sealant. ${ }^{10}$

An in vitro study conducted by Kantovitz et $\mathrm{al}^{13}$ aimed to test the enamel mineral loss inhibition ability at the enamel/sealant interface by fluoride-containing (both GIC- and resin-based) and nonfluoride-containing sealants. The results demonstrated that resin sealant did not prevent enamel mineral loss, contrary to GIC, which showed the highest capacity for fluoride release. They concluded that the presence of fluoride in a material's composition per se does not indicate its capability to prevent the development of enamel caries-like lesions. ${ }^{13}$

\section{Comparison between Aegis ${ }^{\circledR}$ and Conseal-FTM in inhibition of Enamel Demineralization}

Similar to previous studies, our results demonstrated that both agents were found to be effective in the prevention of enamel demineralization. ${ }^{2,5,6}$ However, in this study, the results showed that Aegis ${ }^{\circledR}$ had higher surface microhardness mean values than Conseal-FTM after acid challenge and lower mean difference between pre- and postacid challenge values.

Amorphous calcium phosphate-containing materials have many advantages over fluoride-releasing materials: (1) Results of quantitative microradiographic study demonstrated that remineralization of subsurface enamel lesions by fluoride is a self-limiting surface phenomenon that prevents penetration of ions into the depth of the lesion. Mineral deposition occurred in the initial 30\% of the lesion only. Thereafter, it occludes the surface pores and limits the repair of the remainder of the lesion. On the contrary, ACP-containing materials deliver minerals deeper into the lesion and deposit significantly more mineral overall than fluoride-releasing materials. ${ }^{3}$ (2) The effect of the fluoride ion may be limited by the availability of the $\mathrm{Ca}$ and $\mathrm{PO}_{4}$ in the plaque and saliva in the oral cavity, whereas the high solubility of ACP makes it dissolve as $\mathrm{Ca}$ and $\mathrm{PO}_{4}$ ions, thereby supersaturating the area locally and promoting the formation of HAP. ${ }^{14}$ (3) ACP-containing materials are "smart" materials, i.e., they release $\mathrm{Ca}$ and $\mathrm{PO}_{4}$ ions only when the $\mathrm{pH}$ drops below 5.5 and ceases when the $\mathrm{pH}$ rises, ${ }^{15}$ whereas the pattern of fluoride release from dental material tends to show the greatest amount of fluoride release in the first 24 hours after mixing and then fall sharply on the second day and decreases slowly over the following days. ${ }^{11}$

\section{CONCLUSION}

Within the limitations of this in vitro study, the following conclusions can be drawn:
- The ACP-containing pit and fissure sealant demonstrated the highest inhibition in enamel demineralization when compared with the other types of fissure sealants.

- Fluoride-containing sealants may provide some protective effect on demineralization of adjacent enamel compared with conventional sealants without fluoride.

\section{REFERENCES}

1. Skrtic D, Hailer AW, Takagi S, Antonucci JM, Eanes ED. Quantitative assessment of the efficacy of amorphous calcium phosphate/methacrylate composites in remineralizing carieslike lesions artificially produced in bovine enamel. J Dent Res 1996 Sep;75(9):1679-1686.

2. Silva KG, Pedrini D, Delbem AC, Ferreira L, Cannon M. In situ evaluation of the remineralizing capacity of pit and fissure sealants containing amorphous calcium phosphate and/or fluoride. Acta Odontol Scand 2010 Jan;68(1): 11-18.

3. Langhorst SE, O'Donnell JNR, Skrtic D. In vitro remineralization effectiveness of polymeric ACP composites: quantitative micro-radiographic study. Dent Mater 2009 July;25(7): 884-891.

4. Schumacher GE, Antonucci JM, O'Donnell JNR, Skrtic D. The use of amorphous calcium phosphate composites as bioactive basing materials. Their effect on the strength of the composite/adhesive/dentin bond. J Am Dent Assoc 2007 Nov;138(11):1476-1484.

5. Choudhary P, Tandon S, Ganesh M, Mehra A. Evaluation of the remineralization potential of amorphous calcium phosphate and fluoride-containing pit and fissure sealants using scanning electron microscopy. Indian J Dent Res 2012 Mar-Apr;23(2):157-163.

6. Alsaffar A, Tantbirojn D, Versluis A, Beiraghi S. Protective effect of pit and fissure sealants on demineralization of adjacent enamel. Pediatr Dent 2011 Nov-Dec;33(7):491-495.

7. Gonzales-Cabezas C, Fontana M, Dunipace AJ, Li Y, Fischer GM, Proskin HM, Stookey GK. Measurement of enamel remineralization using microradiography and confocal microscopy. Caries Res 1998;32(5):385-392.

8. Kashet S. Historical review of remineralization research. J Clin Dent 1999;10:56-64.

9. Vatanatham K, Trairatvorakul C, Tantbirojn D. Effect of fluoride- and nonfluoride-containing resin sealants on mineral loss of incipient artificial carious lesion. J Clin Pediatr Dent 2006 Summer;30(4):320-324.

10. Salar DV, García-Godoy F, Flaitz CM, Hicks MJ. Potential inhibition of demineralization in vitro by fluoride-releasing sealants. J Am Dent Assoc 2007 Apr;138(4):502-506.

11. Garçía-Godoy F, Summitt JB, Donly KJ. Caries progression of white spot lesions sealed with an unfilled resin. J Clin Pediatr Dent 1997 Winter;21(2):141-143.

12. Zhou SL, Zhou J, Watanabe S, Watanabe K, Wen LY, Xuan K. In vitro study of the effects of fluoride-releasing dental materials on remineralization in an enamel erosion model. J Dent 2012 Mar;40(3):255-263.

13. Kantovitz KR, Pascon FM, Correr GM, Borges AF, Uchôa MN, Puppin-Rontani RM. Inhibition of mineral loss at the enamel/ 
sealant interface of fissures sealed with fluoride- and nonfluoride containing dental materials in vitro. Acta Odontol Scand 2006 Nov;64(6):376-383.

14. SkrticD,AntonucciJM,EanesED,EichmillerFC,SchumacherGE. Physicochemical evaluation of bioactive polymeric composites based on hybrid amorphous calcium phosphates. J Biomed Mat Res 2000;53(4):381-391.

15. $\mathrm{Xu} \mathrm{HH}$, Weir MD, Sun L. Calcium and phosphate ion releasing composite: effect of $\mathrm{pH}$ on release and mechanical properties. Dent Mater 2009 Apr;25(4):535-542. 